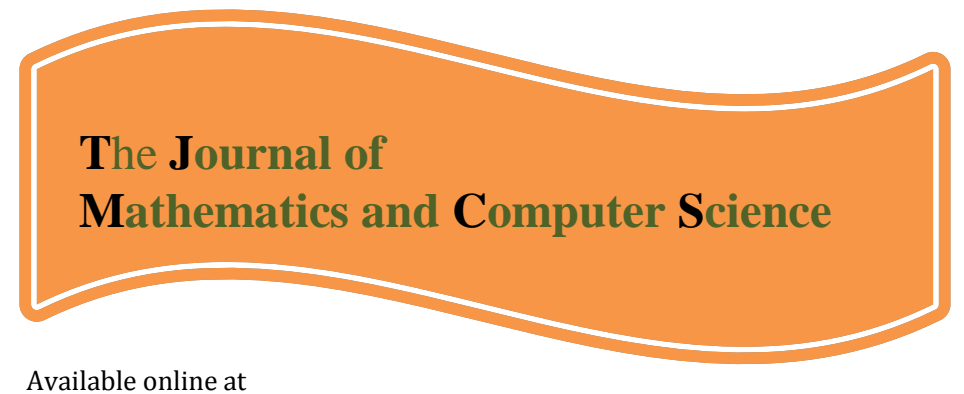

Available online at

\title{
http://www.TIMCS.com
}

The Journal of Mathematics and Computer Science Vol .5 No.3 (2012) 197-204

\section{Incubator with Fuzzy Logic}

\author{
Seyed Kamaleddin Mousavi Mashhadi \\ University of Science and Technology, Faculty of Electric Engineering, Tehran, Iran \\ Sk_Mousavi@iust.ac.ir \\ Jamal Ghobadi dizaj yekan \\ Khorasan Institute of Higher Education, Mashhad, Iran \\ Jamal_Ghobadi@yahoo.com \\ Mehdi Ghasem Nejad Dashtaki \\ Khorasan Institute of Higher Education, Mashhad, Iran \\ Mehdi.Ghasemnejad@gmail.com
}

Received: February 2012, Revised: November 2012

Online Publication: December 2012

\begin{abstract}
Today by increasing population growth, poultry farming has found an important place, one of these solution for poultry farming is to using incubator. Today one the main methods in incubation industry that works smart, this system can be fuzzy logic. In this article we plan to study getting fuzzy of three parameter such as temperature, moisture and oxygen that they have an effective role in the incubation process in incubator. Also in this article we tries to achieve to the greatest efficiency in terms of number of born chickens which was born from eggs and have a system with precise control- finally we survey the average of regression of these three fuzzy parameter.
\end{abstract}

Keywords: Fuzzy Controller; Heater; Humidity; Oxygen; PID Controller ;Temperature.

\section{Introduction.}

Poultry have been popular in Iran from the past. Today, according to the growth of human population and human needs, we should use artificial methods of the mass production in the short timescales to be responsive to the community needs. So, using new methods is essential for more and better poultry production that are depends on them. In this regard, can be used its industrial methods that means using artificial incubation, it was many years that technology of control devices which used in incubation works, have been created. Fundamental factors and key are known for being successful in artificial incubation during the incubation of eggs should be rotated. it is necessary to control the heat, humidity and ventilation and no abrupt changes (shock), occur. 
Among the environmental conditions, temperature is very important than other factors. The last result of birds rising of both quantitative and qualitative is related to the fetal temperature. In this machine by controlling some of the physical processes and natural to be simulated a kind of bird when it is going to breeding.

\section{Construction of incubator}

In the building of all incubators the following points should be observed:

1- Produce smoothly heat and regulation it

2- Produce smoothly moisture and control it

3- Create the proper air ventilation

4- Regular rotation of the eggs

\section{Temperature topic}

Incubation is different from heat source. Natural gas and fossil fuels like oil or gasoline (of course this source virtually is obsolete), and electrical power and... .

The features of good heating system for incubator:

1- To be Appropriateness with the dimensions and the size of incubation machines.

2- Appropriate Distance in to the eggs.

3- High efficiency.

4- Provide the required and Operating Temperature of machine in the shortest time without entering heat shock to the eggs and embryos.

5- Heat smoothly distribution so that all eggs placed in the same conditions and normal temperature.

The main points in the construction machine incubation is chosen the heat source proportional to the size of Incubation chamber So that should have the ability to providing necessary heat of chamber in the shortest possible time without entering heat shock to the eggs. It is better that the heat source to be installed at the top of chamber and with the proper distance from eggs to avoid heat shock in to the eggs.

In this incubator we use heater for heat source and also used a Thermometry to investigate temperature and control. The thermometry should be placed in appropriate place that show the correct temperature of eggs.

\section{Humidity topic}

In this discussion, two issues must be considered:

1- Humidity produce

2- Control and regulate it

Water is the only source of humidity, humidity produce from water is possible from different methods, the most primitive kind is to put a water dish in incubator that make humidity if we can regulated the water level specific and measure its amount with a simple moisture meter, More favorable way can be monitored on the requirements Moisture of The incubation process. IN developed devices use humidifiers device or fog maker or cold steam or Ultrasonic that based on the Electronic circuits with specific techniques But in a small surface can be used a normal water bowl the location of bowl should be near the heat source that they Used the heat source to produce steam Also is a good place to be inhibited that not causes To wetting the place. the Container size is so that it will have evaporating water as a one night and It is not necessary in a short distance from the water-filled can do a work that Filling the water container is from out In moisture production Prevent to formation drop and getting wet the environment is very important. To control the Humidity by a digital measuring device (Psychomotor), the moisture content is measured; 
temperature on the Incubation machine is caused water evaporating from the eggs and fetal loss. Hence it is very important to pay attention to proper moisture. On the other hand, moisture reduction of incubation machine lead to increased evaporation and air bags are becoming more widespread in the eggs.so, the bird tip reaches early to air chamber. Also the moisture increases has been cause late extent of air bag and at this time the chicks will not be able to breath. The moisture Incubation machine depends on its temperature and ventilation speed.

\section{Ventilation and its importance in incubation}

The main problem with the oxygen in the air around the egg dioxide is produced from the other sub-issues such as uniform distribution of heat and moisture in the air more functions. An egg during 21 days within incubation devices uses about 4 liters of oxygen and produces about 3 liters carbon dioxide that by the pores In eggshell the exchange will occurs. On the other hand 100 eggs needs to one-tenth to three cubic meters of oxygen and produced seven-tenths cubic meters of carbon dioxide, as an example 100 eggs per hour requires about 3 cubic meters and 100 Turkey eggs needs to 6 cubic meters per hour of fresh air. One of the important factors in designing incubate machines is to consider the flow air within the eggs. The amount of oxygen needed for fetal growth is about 21 percent. For each one percent reduction of oxygen reduce 5 percent amount of given chickens. Also removal of carbon dioxide and its accumulation around eggs will lead to reduce the hatchability. If carbon dioxide concentrations reach 5 percent the percent hatchability will reach to zero. Maximum concentration of carbon dioxide in incubator machine is 5 percent. That in this incubator machine for air conditioning use large fans which are installed back on the device and also for uniform distribution of heat and humidity used small fan on the machine.

\section{Rotate eggs}

Turning the eggs at the specified time naturally has been observed that the mother bird to prevent sticking the Yolk to the shell and the air bag inside the eggs rotates every 35 minutes. on Industrial scale do this every 1 hour for eggs and every 2 to 4 hours for quail eggs by electric motors or pneumatic jacks, How is rotating the eggs is so that Due to the placed a small head of eggs to the bottom on the Incubation system specific rubs angle the rub 45 degrees from horizontal and After the specified time This 45-degree angle towards the horizon Are applied from opposite sides It should be noted The rotation should be done slowly and without vigorous shaking because extreme shaking caused injury to the fetus and reduces the success rate on incubation. The main reason for turning eggs to Prevent sticking the fetus to the eggs shell and animal being die Of course identical distribution of temperature and humidity to all parts of the eggs is other causes of turning. The main part of an engine turning system is with high power and low turning.

\section{Software part}

This section is mainly devoted to the implementation of phase logic. IN this simulation with phase logic help, presented New method for accurate control and continuous to the parameters of system, Three important parameters as temperature, moisture and oxygen are controlled as phase. Selection of input and output functions is based on obtained experiences from the natural system. This section will study in two steps.

1- First step: articles Simulation

2- Second step: Ideas in the article and its simulation

\section{First step: articles simulation}


In a previous article in the input temperature and humidity on the output used 2 heater in the simulation.as in this article used 1 heater for simulation. For this purpose, we've done the following main steps.

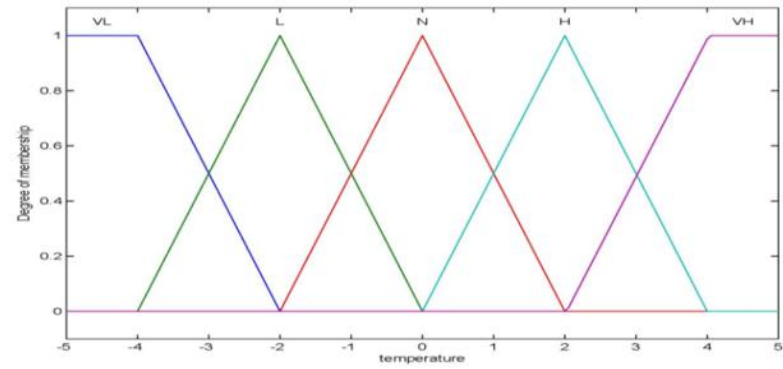

Figure 1: input of temperature difference in terms of Fahrenheit degrees

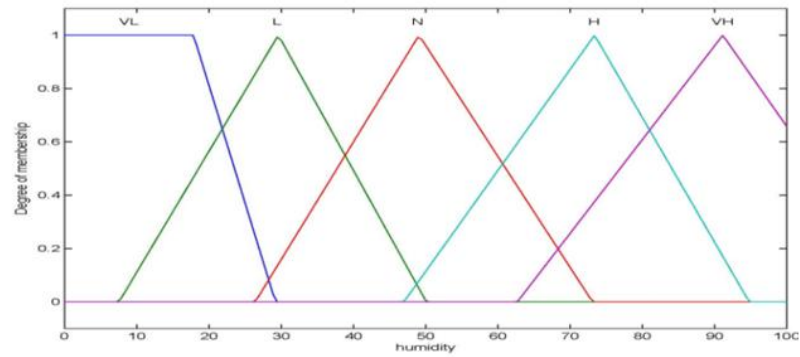

Figure 2: input of temperature difference in terms of percent

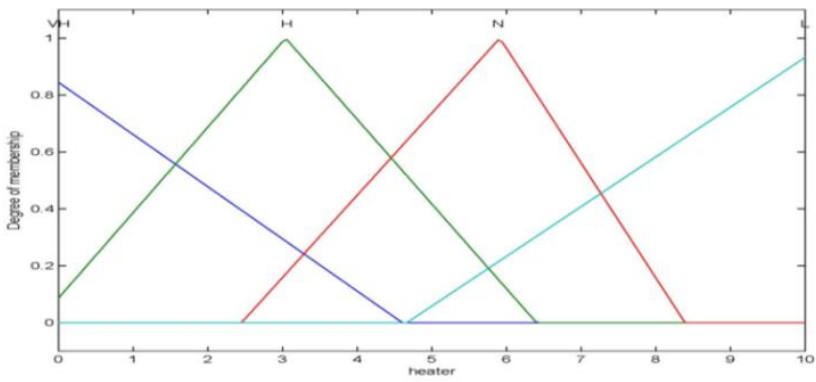

Figure 3: the output of Heater fire angle in terms of milliseconds

Table 1- the Bank of heater fire output angle

\begin{tabular}{|c|c|c|c|c|c|}
\hline $\begin{array}{c}\Delta \mathbf{T} \\
\Delta \mathbf{H}\end{array}$ & $\mathbf{V L}$ & $\mathbf{L}$ & $\mathbf{N}$ & $\mathbf{H}$ & $\mathbf{V H}$ \\
\hline $\mathbf{V L}$ & VH & VH & VH & VH & VH \\
\hline L & H & H & H & H & H \\
\hline N & N & N & N & N & N \\
\hline H & L & L & L & L & L \\
\hline VH & L & L & L & L & L \\
\hline
\end{tabular}

For each pair of input - output, membership values in phase sets adapted the input and output, respectively, according to figures 1 and 2, and 3. This membership function is defined based on knowledge and experience then have been adjusted based on system performance. Hence, the rules if- then define phased and rules bank as below table. The basic rules of knowledge are created unconscious and Set and its complement is done with the help of both conscious and unconscious 
knowledge set. In below table $\Delta \mathrm{T}$ Represents the temperature difference and $\Delta \mathrm{H}$ is indicative the moisture Difference. Also VL expresses very low, L little, $\mathrm{N}$ normal, $\mathrm{H}$ high and VH very high. Also surface Is simulated in Figure 4.

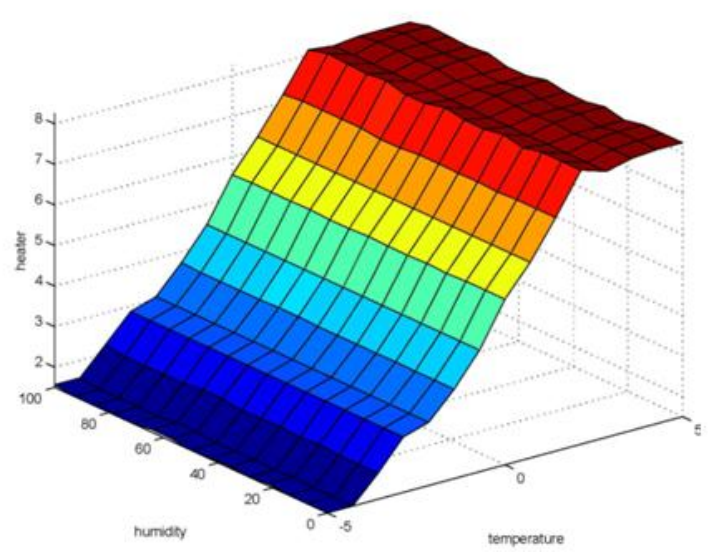

Figure 4: simulated surface

\section{Second step: Ideas in the article and its simulation}

The idea in this article is to measure the oxygen parameter that Oxygen is measured by the sensor When the needed oxygen for eggs reduced Fan will start to work when the amount of oxygen required to reach the fan is off The simulation is as follow.

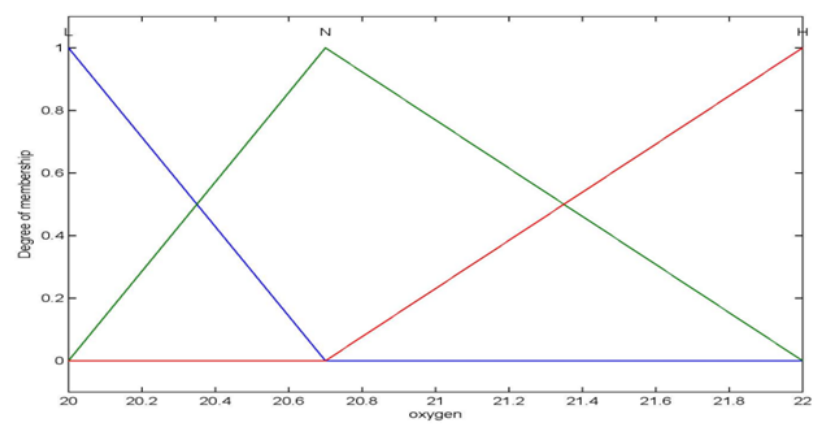

Figure 5: input of oxygen differences in percentage

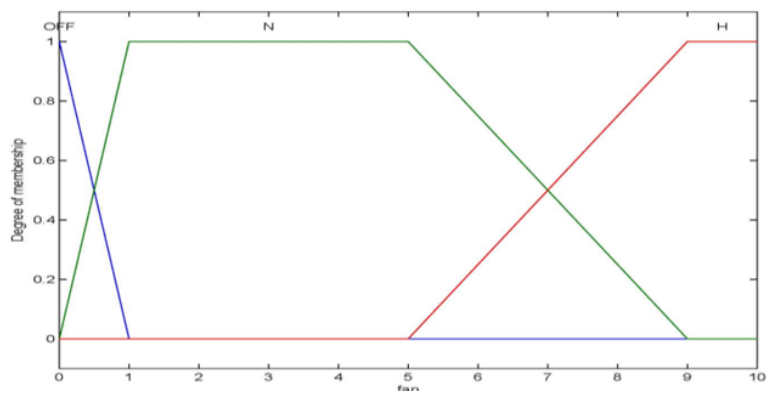

Figure 6: Fire output angle in terms of Millisecond

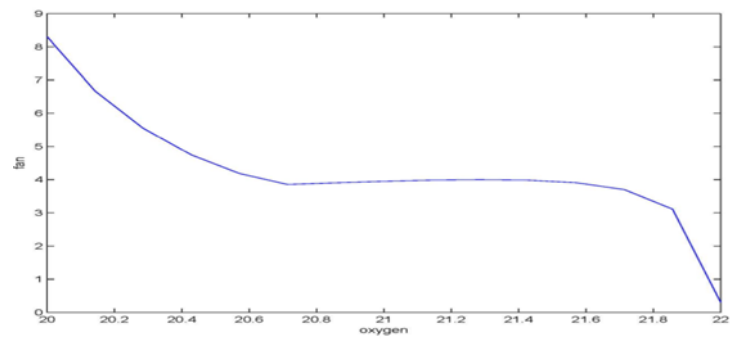

Figure 7- simulated surface

Table 2: bank rules out firing angle fan 


\begin{tabular}{|c|c|c|c|}
\hline Oxygen & L & N & H \\
\hline Fan & H & N & OFF \\
\hline
\end{tabular}

\section{Regression}

For the presented fuzzy control in the first stage First input, second and output can be reached to the following equation:

$\mathrm{F}(\mathrm{x}, \mathrm{y})=5.57+1.302 \mathrm{x}-0.0005078 \mathrm{y}-0.03464 \mathrm{x} 2-0.0001035 \mathrm{xy}-0.04637 \mathrm{x} 3+0.0001217 \mathrm{x} 2 \mathrm{y}+$ $0.0002794 x 4+1.243 e-006 x 3 y+0.0008519 x 5-4.636 e-006 x 4 y$

This equation has a mean square error of the fuzzy controller:

RMSE: 0.1044

Its surface display as below:

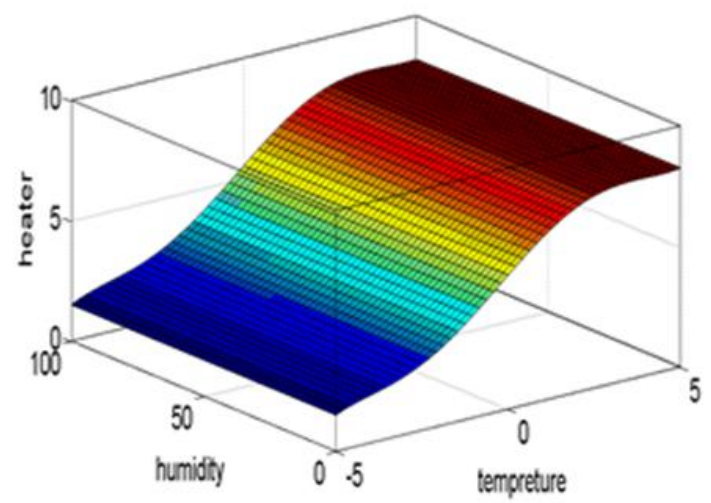

Figure 8: regression surface in first step

Table 3: Compare the obtained results from fuzzy in first stage

\begin{tabular}{|c|c|c|c|}
\hline Temperature & Humidity & $\begin{array}{c}\text { Heater } \\
\text { (Fuzzy) }\end{array}$ & $\begin{array}{c}\text { Heater } \\
\text { (Regression) }\end{array}$ \\
\hline 1 & 2 & 6.66 & 6.79 \\
\hline 2 & 4 & 8.25 & 7.69 \\
\hline 4 & 6 & 8.25 & 8.19 \\
\hline
\end{tabular}

For represented fuzzy controller in second step, input and output can reach to the following equation:

$\mathrm{F}(\mathrm{x})=-0.05155 \mathrm{x} 8-0.3196 \mathrm{x} 7-0.124 \mathrm{x} 6+0.9942 \mathrm{x} 5+0.6572 \mathrm{x} 4-1.742 \mathrm{x} 3+0.04566 \mathrm{x} 2+0.4432 \mathrm{x}$ $+3.929$

This equation has a mean square error of the fuzzy controller:

RMSE: 0.04462

Its surface display as below: 
S.K. Mousavi, J. Ghobadi, M. Ghasem Nejad / TJMCS Vol .5 No.3 (2012) 197-204

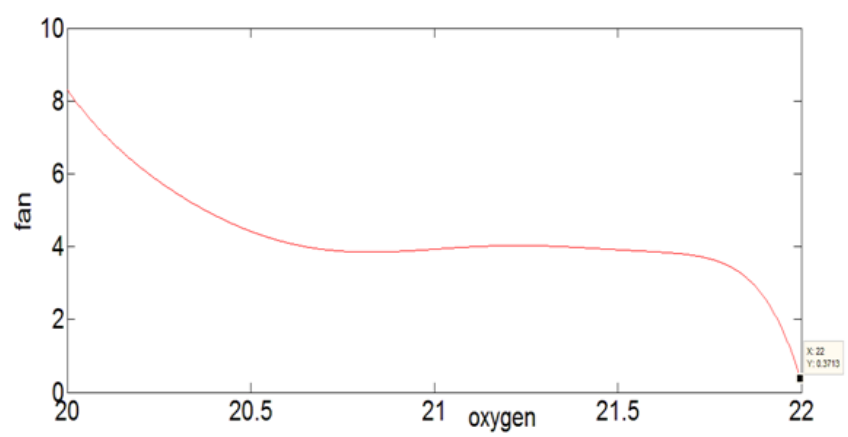

Figure 9: Regression surface in second step

Table 4: Compare the obtained results from fuzzy in second stage

\begin{tabular}{|c|c|c|}
\hline Oxygen & Fan & Fan \\
(Fuzzy) & (Regression) \\
\hline 20 & 8.31 & 8.24 \\
\hline 21.3 & 4 & 4.01 \\
\hline 22 & 0.304 & 0.3 \\
\hline
\end{tabular}

\section{Conclusions}

In this simulation we use a heater because by Placing the heater near a water container causing water evaporation and necessary moisture to be provide for the eggs but in article by putting a heater in the water dish it caused quickly evaporate the water so it increases the moisture That moisture increases caused airbag late extent at this time chicks will not be able to breathe so The efficiency reduced. I also added oxygen parameter to the article and oxygen like temperature and moisture is one of the important factors for eggs. The needed oxygen for fetus growth is 21 percent. For each every 1 percent reduction of oxygen reduce 5 percent amount of chickens. Also not removing carbon dioxide and its accumulation around eggs will lead to a decrease in percentage hatchability. If carbon dioxide concentrations reach to $5 \%$ the percent of hatchability will be zero, so by placing these parameters increase the efficiency.

\section{References}

[1] Lie Wang, Fuzzy Systems and Fuzzy Control, Mohmmad Teshne Lab - Dariush Ofyuni - Nima Safarpour, Khaje Nasir Toosi University Press, 1378

[2] Seyed Mostafa Kia, Fuzzy Logic in MATLAB, Persian Gulf Publishing, 1389

[3] Mehdi Hedayati, applied anatomy and physiology of birds, publishing Mohammadi, 1389

[4] S.V. Kartalopoulos, fuzzy logic and neural networks (Concepts and Applications), Mahmoud Jvrabyan - Mercy of ... Smart, Shahid Chamran University Press, 1381

[5] Jasmin Velagic, Nedim Osmic, Kemal Lutvica, Nihad Kadic "Incubator System Identification and Temperature Control with PLC \& HMI" 52nd International Symposium ELMAR-2010, 15-17 September 2010, Zadar, Croatia, pp 309 - 312, 2010

[6] Wu Shu-ci, Zhou Guo-xiong, Yan Mi-ing,"Research of Hybrid Intelligent Control for Incubation"10th Intl. Conf. on Control, Automation, Robotics and Vision Hanoi, Vietnam, 17-20 December 2008, pp 2026-2030, 2008. 
[7] M. K. GINALSKI, A. J. NOWAK, L. C. WROBEL "Modelling of heat and mass transfert processes in neonatology", Biomedical Materials, vol. 3, pp.1-11, 2008.

[8] K. Lutvica, "Temperature control in electric oven," Bachelour tesis,Faculty of Electric Engineering Sarajevo, 2009. 